\title{
A ESPECIFICIDADE DA NORMAS FAMILIARISTAS SOB O VIÉS DA DOUTRINA BRASILEIRA E PORTUGUESA
}

\author{
Maísa de Souza Lopes ${ }^{1}$ \\ Vivian Gerstler Zalcman²
}

\begin{abstract}
RESUMO: O Direito de Família é um dos ramos mais estudados da civilística. Ainda assim, pouca atenção é dada às características das normas familiaristas, cujo enfoque se pretende no presente. Os temas centrais do artigo são: a polêmica sobre o enquadramento do Direito de Família no âmbito do direito privado, seus caracteres particularizados e as implicações decorrentes dessa especificidade, e a sua classificação como um direito subjetivo. $O$ estudo que se propõe será realizado sob o viés da doutrina brasileira e portuguesa. A metodologia que será aplicada na pesquisa é a hipotético-dedutiva. Ademais, a pesquisa será essencialmente bibliográfica e documental.
\end{abstract}

Palavras-chave: Direito de Família; Natureza Jurídica; Especificidade; Doutrina Brasileira; Doutrina Portuguesa

\section{THE SPECIFICITY OF FAMILIARIST RULES UNDER THE VIENUS OF THE BRAZILIAN AND PORTUGUESE DOCTRINE}

\begin{abstract}
Family law is one of the most studied branches of civilization. Even so, little attention is paid to the characteristics of familiaristic norms, whose focus is intended in the present. The central themes of the article are: the controversy about the framing of Family Law within the scope of private law, its particularized characteristics and the implications deriving from this specificity, and its classification as a pure subjective right. The study that is proposed will be carried out under the bias of Brazilian and Portuguese doctrine. The methodology that will be applied in the research is hypothetico-deductive. In addition, the research will be essentially bibliographical and documentary.
\end{abstract}

Keywords: Family right; Legal Nature; Specificity; Brazilian Doctrine; Portuguese Doctrine

\footnotetext{
${ }^{1}$ Doutoranda e mestre em Direito pela Faculdade Autônoma de Direito de São Paulo - Fadisp. Advogada atuante em Mato Grosso do Sul. Professora de Direito Civil do Centro Universitário Anhanguera Campo GrandeMS. maisalopes@outlook.com

${ }^{2}$ Mestre em Direito pela PUCSP. Advogada atuante em São Paulo. Professora de Direito. Autora de livros e artigos jurídicos publicados em âmbito nacional. vivianzalcman@hotmail.com.
} 


\section{INTRODUÇÃO}

O Direito de Família é, sem dúvidas, um dos temas de Direito Civil que mais tem sofrido transformações nos últimos tempos. Muito se fala sobre a modificação da arquitetura familiar e seus institutos, mas pouca atenção é dada às características das normas familiaristas e suas consequências, cujo enfoque se pretende no presente.

Assim, os temas centrais do artigo vertente são: a polêmica sobre o enquadramento do Direito de Família no âmbito do direito privado, as intersecções e limitações de ordem pública, que lhe propiciam uma natureza jurídica diferenciada, seus caracteres particularizados e as implicações decorrentes dessa especificidade, e, por fim, a análise da sua não classificação como um direito subjetivo puro.

O estudo que se propõe será realizado sob o viés da doutrina brasileira e portuguesa, para se conceber criticamente as questões estruturantes desse ramo e ainda verificar de que modo a mencionada doutrina estrangeira pode contribuir para a investigação, servindo como fonte de possibilidades e soluções de indagações.

O problema da pesquisa é em que medida essas idiossincrasias distinguem-no dos demais ramos da civilística e quais os efeitos resultantes desse exame. O objetivo é contribuir com o exame da teoria geral do Direito de Família, cuja compreensão é primordial para uma reflexão aperfeiçoada desse instituto na atualidade.

A metodologia que será aplicada na pesquisa é a hipotético-dedutiva, pois planeja-se a partir do estudo das doutrinas brasileiras e portuguesas, concluir quanto se pode beber nas suas fontes e extrair algum aprendizado. Ademais, a pesquisa será essencialmente bibliográfica e documental.

\section{O DIREITO DE FAMÍLIA: ENQUADRAMENTO GERAL}

Assim como a família, também o direito da família tem sofrido grandes transformações ao longo da sua história. Essas alterações, muitas vezes, são reflexos das modificações sociais, 


\section{A ESPECIFICIDADE DA NORMAS FAMILIARISTAS SOB O VIÉS DA DOUTRINA BRASILEIRA E PORTUGUESA}

culturais e políticas, noutras vezes, é o legislador que, através de rupturas legislativas, pretende fomentar as referidas mudanças ${ }^{3}$.

O Direito de Família é um dos ramos do Direito, portanto, de maior incidência prática ou aplicabilidade e se destaca pelo interesse que desperta na maioria das pessoas, isso porque, de uma forma ou de outra, todos procedem de uma família, e vivem, quase sempre, em um conjunto familiar.

Antigamente, dizia-se que se tratava da seção do Direito que envolve o conjunto de regras aplicáveis às relações entre pessoas ligadas pelo casamento, pelo parentesco, pela afinidade e pela adoção. Contudo, melhor dizer que versa sobre o conjunto de normas e princípios que disciplinam ou regulam o conjunto familiar.

E, conforme a sua finalidade ou o seu objetivo, as normas familiaristas ora regulam as relações pessoais entre os cônjuges (e companheiros), ou entre os ascendentes e os descendentes ou entre parentes fora da linha reta; ora disciplinam as relações patrimoniais que se desenvolvem no seio da família, englobando as que se passam entre cônjuges, entre pais e filhos, entre tutor e pupilo ${ }^{4}$.

O seu conteúdo envolve o direito matrimonial (daí resultando o regramento do matrimonio), o convivencial (abrangendo o regulamento da união estável), o parental (que disciplina os vínculos decorrentes do parentesco e da filiação) e o assistencial (que abrange as relações de assistência entre os familiares, v.g. os alimentos).

No sentido técnico-jurídico, encontra-se na legislação as fontes do Direito de Família. Sua fonte principal é a norma constitucional, que nos artigos 226 e 227, estabelece regras e princípios norteadores (veja-se alguns deles: da pluralidade das entidades familiares, da igualdade entre homem e mulher, da igualdade entre os filhos).

${ }^{3}$ SOUSA, Miguel Teixeira. Do direito da Família aos Direitos Familiares.

${ }^{4}$ PEREIRA, Caio Mário da Silva. Instituições de direito civil. Rio de Janeiro: Forense, 2012, p. 38. Ainda sobre sua finalidade, Carlos Martínez de Aguirre Aldaz frisa que "es permitir que la familia cumpla sus funciones sociales del mejor modo posible. Esta misma perspectiva funcional sirve para valorar tanto los diferentes modelos familiares, como las distintas regulaciones jurídicas del matrimonio y la família: (...).” ALDAZ, Carlos Martínez de Aguirre. Curso de Derecho Civil. Volume IV. 2a ed. Zaragoza: Editorial Colex, 2008, p. 26. 
Em nível infraconstitucional, pode-se destacar: o Código Civil, a Lei nº ${ }^{\circ}$ 6.515/77 (Lei do Divórcio), a Lei $n^{\circ}$. 8.56092 (Lei da Investigação de Paternidade), a Lei $n^{\circ}$. 8.069/90 (Estatuto da Criança e do Adolescente), Lei no . 10.257/01 (Estatuto do Idoso), Lei n ${ }^{\circ}$. 12.010/09 (Lei Nacional da Adoção), dentre outras.

O Direito de Família apresenta certas peculiaridades que o singulariza e o diferencia de qualquer outro ramo do Direito. Isso visto que, o seu objeto de estudo tem uma dimensão jurídica de extrema relevância e incidência social, conforme se verá, quando será possível apreender seu espírito e sentido próprios, o que se objetiva.

\section{A NATUREZA JURÍDICA E AS CARACTERÍSTICAS DAS NORMAS DO DIREITO DE FAMÍLIA: SUA ESPECIFICIDADE}

O Direito de Família integra uma parte do Direito Civil e, portanto, é classificado como Direito Privado. Não obstante, existe uma tendência doutrinária de considerá-lo como um ramo do Direito Público, devido à predominância de normas impositivas que retiram das partes a plena autonomia privada, tão essencial ao Direito Privado ${ }^{5}$.

Orlando Gomes descreve o ponto de vista de Cicu, que defende a publicização do Direito de Família: segundo este, as relações de família são ordenadas juridicamente com a técnica própria da disciplina das relações de Direito Público e que esse ordenamento está impregnado do espírito que vivifica esse direito, completamente diferente do que insufla o Direito Privado ${ }^{6}$.

Por seu turno, José Luiz Gavião de Almeida alude ao entendimento de João de Oliveira Filho, que não admite derrogação das normas do Direito de Família e fixa o estado das pessoas como coisa fora do comércio, o que seria suficiente para justificar a natureza publicista das relações familiares ${ }^{7}$. 


\section{A ESPECIFICIDADE DA NORMAS FAMILIARISTAS SOB O VIÉS DA DOUTRINA BRASILEIRA E PORTUGUESA}

Realmente, constata-se, do exame das normas familiaristas, que há certa limitação no poder de disponibilidade dos direitos, isto é, há muitas normas que são inderrogáveis pela vontade dos particulares. Isso significa que as partes não podem decidir ou pactuar algo diferente do estabelecido na lei.

Convém esclarecer que as relações jurídicas familiares nascem de atos voluntários, que se submetem às normas regentes dos atos jurídicos, mas a vontade só se manifesta na sua realização, uma vez que seus efeitos já estão preestabelecidos na lei ${ }^{8}$.

Com efeito, não é possível alterar o conteúdo do casamento (v.g., modificar os deveres conjugais); ou sujeitar a termo ou condição o reconhecimento do filho; ou alterar o conteúdo das responsabilidades parentais; ou renunciar definitivamente aos alimentos, mormente quando envolva direito de menores ou incapazes ${ }^{9}$.

Rolf Madaleno, ilustre jurista brasileiro, contrapõe a questão da restrição da autonomia privada, nestes termos ${ }^{10}$ :

O Direito de Família justamente destoa do restante do Direito Privado quando, com as exceções dos divórcios extrajudiciais da Lei n. 11.441/2007, limita a autonomia privada com a imperatividade de suas normas, todas elas coerentes com o propósito de manutenção e preservação dos direitos pessoais presentes nas relações jurídicofamiliares, cujo enfoque diverge da livre movimentação individual encontrada no campo das relações de cunho exclusivamente patrimonial e econômico; mas isso não conduz à conclusão de o Direito de Família pertencer ao Direito Público, até porque já ficou demonstrado o fracasso do intervencionismo do Estado na vida familiar e na intimidade das pessoas.

Arnaldo Rizzardo, por outro norte, fundamenta que a íntima aproximação ao Direito Público não retira o caráter privado do Direito de Família, pois as relações disciplinadas adstringem-se às pessoas físicas, sem obrigar o ente público na solução dos litígios; e que a proteção à família não vai além de mera tutela, não acarretando a responsabilidade direta do Estado na observância ou não das regras correspondentes pelos cônjuges e demais sujeitos ${ }^{11}$.

${ }^{8}$ DINIZ, Maria Helena. Curso de direito civil brasileiro, volume 5: direito de família. 30ª ed. São Paulo: Saraiva, 2015, p. 44.

${ }^{9}$ RIZZARDO, Arnaldo. Direito de família. 9 ed. Rio de Janeiro: Forense, 2014, p. 5.

${ }^{10}$ MADALENO, Rolf. Curso de direito de família. $5^{\mathrm{a}} \mathrm{ed}$. rev, atual e ampl. Rio de Janeiro: Forense, 2013, p. 36.

${ }^{11}$ RIZZARDO, Arnaldo. Direito de família. 9 ed. Rio de Janeiro: Forense, 2014, p. 5. 
Há outros doutrinadores que, convencidos de que os preceitos reguladores das relações familiares não são de Direito Privado nem de Direito Público, sustentam serem de Direito Social, uma vez que tanto protegem de modo imediato os interesses dos organismos sociais como regula as relações dos homens como seres sociais ${ }^{12}$.

No entanto, não se poderia classificar todas as normas do Direito de Família como de Direito Social, posto que diversas são de estrito direito individual, destinadas a tutelar os interesses particulares dos indivíduos como tais, para o desenvolvimento de sua personalidade individual, a despeito do seu enquadramento no grupo familiar ${ }^{13}$.

Encontra-se, ainda, uma outra posição, dos que são conhecidos como autonomistas, à exemplo de Ruggiero e Maroi, que, sem alterar o nomen iuris da classificação, consideram o Direito de Família um direito singular sui generis, mas que deve ser emancipado, tanto do Direito Privado, como do Público. Por consequência, seria um direito à parte, devendo ser ordenado por um código autônomo, que teria maior afinidade com o Direito Público ${ }^{14}$.

Na doutrina Mexicana, há entendimento parecido, Julián Guitrón Fuentevilla argumenta que a natureza jurídica do Direito de Família é a de um terceiro gênero, ao lado do Público e do Privado, pois não pode ser considerado nem como Direito Social, nem como Civil, mas sim como um novo ramo jurídico, com princípios e objeto de estudo próprios. Esmiúça-se a seguir ${ }^{15}$ :

\begin{abstract}
Para nosotros, el Derecho Familiar tiene su propia naturaliza jurídica. Su ubicación em el mundo del Derecho. Su contenido que no es Privado ni Público, mucho menos Civil. El Derecho Familiar, que no de Familia ni de la Familia, sino com su género Familiar, es uma nueva rama de la ciência del Derecho, com características singulares. Su objeto de estúdio próprio, la família. Sus relaciones jurídicas sometidas al orden público, pero sin ser um organismo del Estado. Sus sujetos - cónyuges, hijos, abuelos, padres, hermanos, madres, primos, divorciados, adoptantes, adoptados, concubinos, emancipados, incapacitados, descapacitados, ausentes, desherdados, herederos, etc se rigen por normas de orden público, que no son las del Estado, que éste se há preocupado por promulgarlas, com características especiales, donde se imponen - el jus imperium - a traves del Derecho.
\end{abstract}

\footnotetext{
12 GOMES, Orlando. Direito de família. Rio de Janeiro: Forense, 2002, p. 6.

${ }^{13}$ GOMES, Orlando. Direito de família. Rio de Janeiro: Forense, 2002, p. 6.

${ }^{14}$ SANTA MARIA, José Serpa de. Curso de direito civil: direito de família, volume VIII. $1^{\text {a }}$ ed. Rio de Janeiro: Freitas Bastos, 2001, p. 31.

${ }^{15}$ FUENTEVILLA, Julián Guitrón. La Naturaleza Jurídica y La Autonomia Del Derecho Familiar. In Derecho de Familia y Registro de La Propriedad. Madrid: Centro de Estudios Registrales, 2001, p. 347.
} 


\section{A ESPECIFICIDADE DA NORMAS FAMILIARISTAS SOB O VIÉS DA DOUTRINA BRASILEIRA E PORTUGUESA}

José Serpa de Santa Maria confronta esses posicionamentos, pois, ainda que insinuante e atraente, exige reflexões mais aprofundadas, do contrário poder-se-ia desencadear o esfacelamento do Direito Civil, dando vazão aos impulsos autonomistas que contaminam outros ramos juscivilistas ${ }^{16}$.

Para pôr fim na discussão, Orlando Gomes assevera que é necessário determinar se o Direito de Família é público ou privado à luz dos critérios tradicionais de distinção, que, embora falhos, são geralmente aceitos, quando menos por interesse didático. Logo, pelos sujeitos das relações que disciplina, pelo conteúdo dessas relações, pelos fins de seu ordenamento e pelas formas de atuação, o Direito de Família é ramo do Direito Privado. Conclui que ${ }^{17}$ :

As relações de família travam-se, realmente, entre particulares. Os direitos e deveres que compreendem exprimem interesses que, embora tutelados elo Estado e sujeitos à sua fiscalização e controle, são de ordem individual. À vista da importância que a organização da família tem para a comunidade, o Estado restringe a autonomia privada, limitando o poder da vontade dos indivíduos, mas como essa intervenção não sacrifica o propósito primeiro da disciplina, que é o de propiciar e fomentar o desenvolvimento da personalidade dos indivíduos. O ordenamento jurídico da família conforma-se, pois, às finalidades essenciais do direito privado, ainda sobrepondo a interesses particulares os do grupo que protege e tutela.

Maria Berenice Dias ressalta que não se pode conceber nada mais privado, mais profundamente humano do que a família, em cujo seio o homem nasce, vive, ama, sofre e morre. A pretensão de deslocar a família do direito privado representa um contrassenso, pois prepara o terreno para um intervencionismo intolerável do Estado na vida íntima ${ }^{18}$.

Sob outro enfoque, Carlos Pamplona Corte Real salienta que o Direito de Família é um ramo de direito privado, o mais “privado dir-se-ia”, ainda que o Estado, reconhecendo a legitimidade dessa privacidade, a deva proteger e tutelar. São seus fundamentos ${ }^{19}$ :

(...) porque o Direito de Família parte da lídima afirmação de uma autonomia pessoal, intimista e geradora de uma convivencialidade perfeitamente recortada pelos sujeitos que a partilham. Nenhum ramo de direito poderá ser mais livre e íntimo que o Direito de Família, cabendo ao Estado, quando muito, a proteção da intimidade da vida familiar. Não será admissível que a vivência familiar possa ser imposta e não fruída. Este é um dos dilemas que veem subsistindo e que levam alguns autores a negar tal evidência, que a Constituição (CRP) bem garante, como se verá, quanto ao cariz da

${ }^{16}$ SANTA MARIA, José Serpa de. Curso de direito civil: direito de família, volume VIII. $1^{\text {a }}$ ed. Rio de Janeiro: Freitas Bastos, 2001, p. 31.

${ }^{17}$ GOMES, Orlando. Direito de família. Rio de Janeiro: Forense, 2002, p. 6.

18 DIAS, Maria Berenice. Manual de direito das famílias. 3 ed. rev, atual e ampl. São Paulo: Editora Revista dos Tribunais, 2006, p.33.

${ }^{19}$ CORTE REAL, Carlos Pamplona. Relance Crítico sobre o Direito de Família português. p. 108. 
tutela da reserva da intimidade da vida familiar e da garantia do direito fundamental de constituir livremente família e de contrair, ou não, casamento (arts. ${ }^{\circ} 26^{\circ}$ e $36^{\circ}$ da CRP).

Contudo, Francisco Pereira Coelho e Guilherme de Oliveira, doutrinadores portugueses, fazem um apontamento interessante, de que há um direito constitucional da família, um direito penal da família, um direito fiscal da família, um direito processual da família, um direito da segurança social da família, e estes são direito público. Finalizam ao assegurar que as relações familiares como as parafamiliares são de direito privado ${ }^{20}$.

A distinção em pauta é útil para efeitos didáticos, motivo pelo qual foi abordada. Ora, é evidente que o Direito de Família possui alguns traços peculiares, que o distingue dos demais ramos da civilística, justamente em razão das polêmicas interseções e limitações de ordem pública comentadas, que serão a seguir detalhadas, para complementar sua categorização.

Os direitos de família são, em regra, direitos pessoais extrapatrimoniais. Existem, conquanto, direitos de família patrimoniais, v.g. os regimes de bens do casamento. Os primeiros são chamados de direitos de família puros, os segundos, de direitos de família aplicados, pela doutrina portuguesa. Contudo, ambos confluem sistematicamente, por exemplo, ao tempo que os filhos devem obediência aos pais, os pais devem alimentos aos filhos.

Os direitos familiares extrapatrimoniais, logo, personalíssimos, revestem-se de características especiais, em sua maioria, são intransferíveis, intransmissíveis, irrevogáveis, irrenunciáveis, inderrogáveis, inalienável e não admitem termo ou condição ${ }^{21}$. Enquanto que as normas que regulamentam interesses patrimoniais de família mantêm certo cunho de disponibilidade.

A respeito do caráter imperativo das normas familiaristas, Jorge Augusto Pais de Amaral assim detalha-o ${ }^{22}$ :

${ }^{20}$ COELHO, Francisco Pereira, OLIVEIRA, Guilherme de. Curso de Direto da Família. 5a ed., Coimbra: Imprensa da Universidade de Coimbra, 2016, p.170.

${ }^{21}$ Citam-se os exemplos, considerados respectivamente, não se admite que alguém transfira sua condição de filho; o filho não transmite o direito de percepção de alimento; não é possível a revogação do ato de filiação; os alimentos não podem ser renunciados, mormente quando se tratar de menores e incapazes; não é possível modificar os deveres conjugais; a filiação não pode ser alienada; e não é possível sujeitar o casamento à termo ou condição.

${ }^{22}$ AMARAL, Jorge Augusto Pais de. Direito da família e das sucessões. $1^{\mathrm{a}}$ ed. Coimbra: Almedina, 2015, p. 17. 
Assim, têm caráter imperativo as normas que regulam as modalidades, os requisitos e a forma do casamento, as que definem os deveres e os direitos pessoais dos cônjuges, as que enumeram os fundamentos do divórcio, as que disciplinam as responsabilidades parentais, o direito a alimentos e o instituto de adoção. De uma forma genérica, pode dizer-se que fogem a esse controlo do Estado as relações familiares patrimoniais, visto que são reguladas, de um modo geral, por normas de caráter dispositivo. No entanto, mesmo dentre estas, existem ainda algumas normas de caráter imperativo. É o caso, entre outros, das restrições ao princípio da liberdade quanto às convenções antenupciais (artigo $1699^{\circ}$ ); da imutabilidade das convenções antenupciais e do regime de bens resultantes da lei (artigo 1714 ${ }^{\circ}$ ); do regime imperativo da separação de bens (artigo $1720^{\circ}$ ).

O Direito da Família é um direito institucional, sendo esta uma qualificação recorrente na doutrina, como observam Francisco Pereira Coelho e Guilherme de Oliveira. Nessa concepção, a lei é só uma das formas de revelação do direito, e porventura a mais infiel, pois o direito vive sobretudo nas próprias instituições ou ordens concretas. Daí que o Direito da Família é um direito institucional porque o legislador se limita, em alguma medida, quando regula as relações de família, a reconhecer esse “direito” que vive e constantemente se realiza na instituição familiar ${ }^{23}$.

Há o predomínio de direitos imprescritíveis ou fora do alcance da decadência, como o direito aos alimentos, de requerer separação ou divórcio, de reconhecimento da paternidade;

Francisco Pereira Coelho e Guilherme de Oliveira apresentam os seguintes exemplos atinentes a esse atributo do Direito de Família: "São imperativas, p. ex., as normas que regulam os impedimentos matrimoniais e, em geral, os requisitos de fundo e de forma do casamento; os direitos pessoais dos cônjuges; as modalidades e as causas do divórcio e da separação de pessoas e bens; os modos de estabelecimento da filiação; as presunções de maternidade e paternidade, o seu valor e o modo como podem ser impugnadas; a atribuição do exercício das responsabilidades parentais, relativamente à pessoa e aos bens dos filhos, e o seu conteúdo essencial; a organização da tutela; as condições e os efeitos da adoção; etc. Pode dizer-se, grosso modo, que apenas as relações familiares patrimoniais são regidas por normas de caráter dispositivo, sendo de salientar, todavia, que ainda que depararmos, não raramente, com normas imperativas, como as dos arts. $1699^{\circ}, 1714^{\circ}, \mathrm{n}^{\circ} .1,1720^{\circ}$, etc." COELHO, Francisco Pereira, OLIVEIRA, Guilherme de. Curso de Direto da Família. $5^{\text {a }}$ ed., Coimbra: Imprensa da Universidade de Coimbra, 2016, p.169.

José João Gonçalves de Proença justifica a adoção de normas imperativas no Direito de Família: "Justifica-se essa imperatividade pela necessidade de assegurar a estabilidade da disciplina das relações familiares, uma vez que se trata de matérias de interesse e ordem pública e que, como tal, não podem ser deixadas ao livre arbítrio dos particulares (v.g. os requisitos do casamento, art. $1601^{\circ}$, as condições para a filiação adoptiva, art. 1973; o conteúdo do poder parental, art. $1878^{\circ}$, etc.). ${ }^{22}$ PROENÇA, José João Gonçalves de. Direito da família. Lisboa: SPB, 1996, p. 29.

${ }^{23}$ COELHO, Francisco Pereira, OLIVEIRA, Guilherme de. Curso de Direto da Família. $5^{\mathrm{a}}$ ed., Coimbra: Imprensa da Universidade de Coimbra, 2016, p.171.

José João Gonçalves de Proença também esclarece a concepção institucionalista, segundo ele a família como que gera o seu próprio direito, limitando-se o legislador, muitas vezes, a reconhecer simplesmente esse direito (dando-lhe força coactiva). Assim, não foi o legislador que criou as normas que impõem certos deveres aos cônjuges nas suas relações recíprocas, ou que prescreveram os deveres dos pais para com os filhos, etc... Tais normas nasceram e formaram-se no seio do próprio agregado familiar, por ação natural e exigência espontânea das necessidades características da vida familiar. E daí que, o conteúdo das normas do Direito da Família seja, em muitos casos, vago, devendo ser completado e integrado pelo recurso às normas institucionais, de essência natural. PROENÇA, José João Gonçalves de. Direito da família. Lisboa: SPB, 1996, p. 31. 
mas há, também, a previsão de caducidade para determinadas ações, v.g. a de anulação do casamento $^{24}$. Alguns direitos de família pertencem a categoria dos direitos potestativos, como o de promover o divórcio e o de contestar a paternidade ${ }^{25}$.

Outra peculiaridade relevante é que os deveres familiares pessoais (dever de respeito entre os cônjuges, dever de cooperação, etc) não estão sujeitos à tutela mais consistente dos deveres jurídicos, que é a possibilidade de o credor exigir do devedor o seu cumprimento e (ou) obter deste uma indenização ${ }^{26}$. De modo que, não é possível se dirigir ao tribunal com o intuito de obrigar o cônjuge faltoso a cumprir, por exemplo, o dever de respeito, do que decorre possuírem uma "garantia jurídica precária”.

Em tese, a sanção para o mencionado descumprimento estaria disposta no próprio Direito de Família. Veja-se que o inadimplemento do dever de assistência poderia ser resolvido com o instituto da obrigação alimentar, outros deveres conjugais, com o divórcio e a separação de pessoas e bens.

Os direitos e negócios familiares estão sujeitos aos numerus clausus, ao contrário do que sucede no Direito das Obrigações, em que vigora o princípio da liberdade contratual, não só quanto ao número dos negócios, como também quanto ao seu conteúdo. Em matéria de Direito de Família, não só se podem celebrar unicamente os negócios previstos em lei, como as relações familiares estão sujeitas, em princípio, a um conteúdo pré-fixado na lei ${ }^{27}$. Esse atributo também é chamado de tipicidade.

Ademais, o Direito de Família possui um conteúdo notadamente ético, impregnado da influência da religião e dos costumes sociais, e é um ordenamento de aplicação formalista, já que vários atos do Direito de Família são solenes e não dispensam a participação da autoridade pública $^{28}$.

\footnotetext{
${ }^{24}$ RIZZARDO, Arnaldo. Direito de família. 9 ed. Rio de Janeiro: Forense, 2014, p. 7.

${ }^{25}$ GOMES, Orlando. Direito de família. Rio de Janeiro: Forense, 2002, p. 16.

141.

${ }^{26}$ CAMPOS, Diogo Leite. Lições de Direito da Família e das Sucessões. Almedina, Coimbra, 1997, p. 145.

${ }^{27}$ CAMPOS, Diogo Leite. Lições de Direito da Família e das Sucessões. Almedina, Coimbra, 1997, p.

Assim, p. ex., não seria válido o contrato, feito por duas pessoas, que estabeleçam serem filha, irmã ou sobrinha da outra.

${ }^{28}$ SANTA MARIA, José Serpa de. Curso de direito civil: direito de família, volume VIII. $1^{\text {a }}$ ed. Rio de Janeiro: Freitas Bastos, 2001, p. 31.
} 


\section{A ESPECIFICIDADE DA NORMAS FAMILIARISTAS SOB O VIÉS DA DOUTRINA BRASILEIRA E PORTUGUESA}

Por último, calha alguns apontamentos sobre o estado de família ou estados pessoais.

A relação conjugal, que nasce do casamento, é institucionalmente estável e tendencialmente perpétua (no caso de crise conjugal, tem-se a possibilidade da sua extinção pelo divórcio). Na relação paterno-filial, há direitos e deveres que perduram para além da maioridade e outros que cessam. Ora, o estado de família reclama a ideia de posição jurídica destinada a durar, reconhecida à pessoa na sua qualidade de membro da família, como o de filho, solteiro, casado, divorciado ou viúvo ${ }^{29}$.

São suas características: a) indisponibilidade, a constituição ou a modificação pode depender da vontade dos interessados (por exemplo, casamento e divórcio), mas o estado como tal é indisponível, o que é uma exigência do regime de segurança e clareza a que a lei o subordina; b) indivisibilidade, a pessoa não pode ter, simultaneamente, dois estados opostos, assim ser, ao mesmo tempo, solteiro e casado; c) imprescritibilidade, não se perde o estado de família pela prescrição; d) a impossibilidade de se determinar um prazo ou condição para o estabelecimento do estado de família.

Miguel Teixeira de Sousa denota que os estados pessoais são eficazes erga omnes, isto é, têm de ser respeitados por todos. Explica que a eficácia erga omnes restringe-se ao estado pessoal, não abrangendo os fundamentos da decisão, assim, por exemplo, o que adquire eficácia erga omnes é o estado pessoal decorrente do divórcio, do estabelecimento da maternidade, não os fundamentos pelos quais o divórcio foi decretado ou a maternidade reconhecida ${ }^{30}$.

José Luiz Gavião de Almeida, com apoio nas lições de Roberto de Rugiero, sintetiza as mencionadas particularidades e acrescenta outras dos direitos concernentes às relações familiares: a) normas de conteúdo essencialmente ético; b) as relações são, em regra, de natureza extrapatrimonial; c) predominam as relações de ordem pessoal; d) há regulamentação legal, que não fica a cargo dos interessados; e) é de natureza substancialmente solene e formal; f) as normas são cogentes ${ }^{31}$.

${ }^{29}$ OLIVEIRA, José Lamartine Corrêa de. MUNIZ, Francisco José Ferreira. Direito de Família. Porto Alegre: Sergio Antônio Fabris Editor, 1990, p. 34.

${ }^{30}$ SOUSA, Miguel Teireira. Do Direito da Família aos Direitos Familiares. In Textos de Direito de Família para Francisco Pereira Coelho. Coord. Guilherme de Oliveira. Imprensa da Universidade de Coimbra, Coimbra, 2016, p. 524.

${ }^{31}$ ALMEIDA, José Luiz Gavião de. Direito civil: família. Rio de Janeiro: Elsevier, 2008, p. 12. 
Assim sendo, a especificidade do Direito de Família é indiscutível. Justamente por essa razão e, ainda, observando que só com especial cautela e profundo conhecimento pode-se penetrar na ordem familiar, o legislador instituiu tribunais especializados para os julgamentos dessas causas: os tribunais de família e menores ${ }^{32}$ (varas de família e infância e juventude, no Brasil).

\section{AINDA SOBRE A NATUREZA JURÍDICA DO DIREITO DE FAMÍLIA: SÃO DIREITOS SUBJETIVOS?}

Ainda sobre a natureza jurídica do Direito de Família, existe uma diferenciação entre os direitos familiares pessoais e patrimoniais que precisa ser consignada. Os direitos patrimoniais da família, embora não fiquem imunes aos atributos próprios da matéria familiar, consistem em direitos obrigacionais e reais. Por seu turno, os direitos pessoais da família não são direitos subjetivos no sentido estrito.

Isso porque, os direitos subjetivos são direitos de exigir de outrem um certo comportamento no interesse do credor, não são direitos que o seu titular possa exercer "como queira”, e os direitos familiares pessoais trazem a noção de direito-dever, poderes-funcionas e direito-função, que o afasta do conceito de direito subjetivo puro.

De início, vale lembrar que o status familiae se compõe de um conjunto de prestações, onerosidades e obrigações à serviço das pessoas que integram a comunidade familiar. Assim, são numerosos os deveres entres os cônjuges, bem como dos pais quanto aos filhos, e porque não dizer, vice-versa.

Logo, o Direito de Família se caracteriza por uma recíproca interpenetração entre direitos e deveres, consentânea com suas finalidades éticas e sociais. Nesse sentido, o espanhol Carlos Martínez de Aguirre Aldaz assevera que é onde pontualmente se observa a fusão de

${ }^{32}$ A Lei de Organização e Funcionamento dos Tribunais Judiciais (Lei n. ${ }^{\circ}$ 62/2013, de 26 de agosto) atribui a secções de competência especializada “de família e menores”, competência para preparar e julgar as questões de direito da família que vêm referidas nos arts. $112^{\circ}, 123^{\circ}$ e $124^{\circ}$; nas comarcas onde não haja tribunal de família e menores, é competente o tribunal de comarca. COELHO, Francisco Pereira; OLIVEIRA, Guilherme de. Curso de Direito da Família. $5^{\text {a }}$ ed, p. 177. 


\title{
A ESPECIFICIDADE DA NORMAS FAMILIARISTAS SOB O VIÉS DA DOUTRINA BRASILEIRA E PORTUGUESA
}

direitos e deveres, de forma que ao se conceder um direito para seu titular, este também deve cumprir um dever que o ordenamento põe a seu $\operatorname{cargo}^{33}$.

Relativamente à ideia de direito-poder, poder-dever, Carlos Lasarte assegura que o comentado ramo do Direito não consiste em direitos subjetivos propriamente ditos, mas, ao contrário, deve qualificar-se como "potestades” (poderes): “cuando los poderes o facultades que ostenta una persona no atienden propriamente a sus intereses particulares, sino que el ejercicio de tales poderes implica tener em consideracion el cuidado y la vigilância o los interesses de otra u otras personas, (...)”34.

No que tange à concepção de direito-função, Francisco Pereira Coelho e Guilherme de Oliveira aclaram que, nos direitos familiares pessoais, “o seu titular é obrigado a exercê-lo, e é obrigado a exercê-lo de certo modo, do modo que for exigido pela função do direito, pelo interesse que ele serve”. A sua função seria a de “favorecer e garantir o cumprimento dos particulares deveres morais que incumbem ao seu titular para com a pessoa contra quem se dirigem" 35 .

Mário Júlio de Almeida Costa corrobora com o conceito de direito-função ${ }^{36}$ :

\begin{abstract}
Pelo contrário, os direitos familiares pessoais apresentam-se como poderes-deveres figura que a ciência jurídica moderna contrapõe àqueles direitos subjetivos de tipo tradicional. Entende-se, hoje em dia, que os poderes do titular de um direito subjectivo estão condicionados pela sua função social, ao mesmo tempo que se alarga o âmbito dos direitos que não são conferidos no interesse próprio, mas no interesse de outrem ou no interesse social. Chegou-se à ideia de direito-função.
\end{abstract}

José João Gonçalves de Proença também desenvolve a questão da função. Alega que os direitos familiares pessoais não são direitos subjetivos do modelo tradicional, são poderes funcionais, porque são atribuídos com a missão específica de alcançar determinados fins, dependendo a legitimidade do seu exercício da prossecução dos objetivos para os quais foram

\footnotetext{
${ }^{33}$ ALDAZ, Carlos Martínez de Aguirre. Curso de Derecho Civil. Volume IV. $2^{\mathrm{a}}$ ed. Zaragoza: Editorial Colex, 2008, p. 29.

${ }^{34}$ LASARTE, Carlos. Derecho de Familia. $11^{\mathrm{a}}$ ed. , p. 10.

${ }^{35}$ COELHO, Francisco Pereira. Oliveira, Guilherme de. Op. Cit., p. 177. No mesmo sentido: VARELA, Antunes, Das obrigações em geral, vol. I, 9a ed, Coimbra: Almedina, 1996, p. 206-208.

${ }^{36}$ COSTA, Mário Júlio de Almeida. Noções Fundamentais de Direito Civil. $4^{\mathrm{a}}$ ed., Coimbra: Almedina, 2006, p. 465.
} 
criados. Destinam-se, por isso, a desempenhar uma função ou a cumprir uma missão por lei imposta aos respectivos titulares ${ }^{37}$.

Portanto, exemplo clássico dessa caracterização é a responsabilidade parental, em que o titular do interesse é o filho e o titular do dever são os genitores (o mesmo ocorre na tutela e na curatela). Convém ressaltar que é natural que exista uma coexistência de interesses entre sujeito ativo e passivo, ainda, que indiretamente.

Assim, os pais, ao sustentarem os filhos, ao educarem-nos, ao aconselharem-nos durante a sua existência, não só estão a satisfazer os interesses destes últimos, como também estão a se realizar como pais ${ }^{38}$. Trata-se de uma via de mão dupla.

Apesar da doutrina não se referir a outro exemplo, tem-se que os direitos recíprocos dos deveres conjugais (art. 1672 ${ }^{\circ}$ CC) também constituem direitos-deveres, direito-função, na mesma linha do exposto.

Dessa forma, a problemática está em torno dos direitos familiares de carácter pessoal, que dada sua natureza complexa e seu conteúdo sui generis, observou-se que não cabem no modelo tradicional de direito subjetivo, devendo ser qualificados como poderes funcionais, poderes-deveres, direito-função, direitos-deveres...

\section{CONCLUSÃO}

O estudo das características das normas familiaristas sob a ótica da doutrina brasileira e portuguesa demonstrou que o assunto traz inesgotáveis questões, apresentou-se suas peculiaridades que o singulariza dos demais ramos do Direito Civil e constatou-se realmente que sua dimensão jurídica é de extrema relevância e incidência social.

A polêmica que envolve o enquadramento do Direito de Família no âmbito do direito privado, perpassa por teorias que o classificam como da seara do direito público, como do

${ }^{37}$ PROENÇA, José João Gonçalves de. Direito da família. Lisboa: SPB, 1996, p.26.

${ }^{38}$ CAMPOS, Diogo Leite. Lições de Direito da Família e das Sucessões. Coimbra: Almedina, 1997, p. 140. 


\section{A ESPECIFICIDADE DA NORMAS FAMILIARISTAS SOB O VIÉS DA DOUTRINA}

BRASILEIRA E PORTUGUESA

direito social, e, ainda, como um direito singular sui generis. Mas observou-se que não se pode retirá-lo do domínio do Direito Civil, campo do direito privado.

Justamente esses traços especiais, que levam à confusão da qualificação das normas familiaristas, por causa das intersecções e limitações de ordem pública comentadas, revelaram as características das referidas normas e complementaram sua categorização, o que contribuiu para sua compreensão.

Por fim, verificou-se que os direitos familiares de carácter pessoal, dada sua natureza complexa e seu conteúdo sui generis, não cabem no modelo tradicional de direito subjetivo, devendo ser qualificados como poderes funcionais, poderes-deveres, direito-função, direitosdeveres...

Conclui-se que no Direito de Família predominam normas imperativas e inderrogáveis, o que é compreensível frente à importância do direito tutelado, assim, há matérias que o legislador pretende subtrair à vontade desses membros, mas há espaço, também, para a autonomia privada, sendo que essas duas características convivem nesse sistema multifacetado, implicando variadas consequências. 


\section{REFERÊNCIAS}

ALDAZ, Carlos Martínez de Aguirre. Curso de Derecho Civil. Volume IV. $2^{\text {a }}$ ed. Zaragoza: Editorial Colex, 2008.

ALMEIDA, José Luiz Gavião de. Direito civil: família. Rio de Janeiro: Elsevier, 2008.

AMARAL, Jorge Augusto Pais de. Direito da família e das sucessões. $1^{\text {a }}$ ed. Coimbra: Almedina, 2015.

CAMPOS, Diogo Leite. Lições de Direito da Família e das Sucessões. Almedina, Coimbra, 1997.

COELHO, Francisco Pereira, OLIVEIRA, Guilherme de. Curso de Direto da Família. $5^{\mathrm{a}}$ ed., Coimbra: Imprensa da Universidade de Coimbra, 2016.

CORTE REAL, Carlos Pamplona. Relance Crítico sobre o Direito de Família português. In Textos de Direito de Família para Francisco Pereira Coelho. Coord. Guilherme de Oliveira. Imprensa da Universidade de Coimbra, Coimbra, 2016.

COSTA, Mário Júlio de Almeida. Noções Fundamentais de Direito Civil. $4^{\mathrm{a}}$ ed., Coimbra: Almedina, 2006.

DIAS, Maria Berenice. Manual de direito das famílias. 3 ed. rev, atual e ampl. São Paulo: Editora Revista dos Tribunais, 2006.

DINIZ, Maria Helena. Curso de direito civil brasileiro, volume 5: direito de família. 30a ed. São Paulo: Saraiva, 2015.

FUENTEVILLA, Julián Guitrón. La Naturaleza Jurídica y La Autonomia Del Derecho Familiar. In Derecho de Familia y Registro de La Propriedad. Madrid: Centro de Estudios Registrales, 2001.

GOMES, Orlando. Direito de família. Rio de Janeiro: Forense, 2002.

LASARTE, Carlos. Derecho de Familia. $11^{\text {a }}$ ed. Madrid: Marcial Pons, Ediciones Jurídicas y Sociales, 2017. 
MADALENO, Rolf. Curso de direito de família. $5^{\text {a }}$ ed. rev, atual e ampl. Rio de Janeiro: Forense, 2013.

OLIVEIRA, José Lamartine Corrêa de. MUNIZ, Francisco José Ferreira. Direito de Família. Porto Alegre: Sergio Antônio Fabris Editor, 1990.

PEREIRA, Caio Mário da Silva. Instituições de direito civil. Rio de Janeiro: Forense, 2012.

PROENÇA, José João Gonçalves de. Direito da família. Lisboa: SPB, 1996.

RIZZARDO, Arnaldo. Direito de família. 9 ed. Rio de Janeiro: Forense, 2014.

SANTA MARIA, José Serpa de. Curso de direito civil: direito de família, volume VIII. $1^{\text {a }}$ ed. Rio de Janeiro: Freitas Bastos, 2001.

SOUSA, Miguel Teireira. Do Direito da Família aos Direitos Familiares. In Textos de Direito de Família para Francisco Pereira Coelho. Coord. Guilherme de Oliveira. Imprensa da Universidade de Coimbra, Coimbra, 2016. 